\title{
Indications of Colonoscopy and Their Diagnostic Yield
}

\author{
MUHAMMAD NAVEED ANWAR ${ }^{1}$, HUMAIRA ACHAKZAI ${ }^{2}$, FAHIMULLAH ${ }^{3}$, WAJEEHA QAYYUM4, ZALAND AHMED \\ YOUSFZAI ${ }^{5}$, MAWARA IFTIKHAR ${ }^{6}$ \\ ${ }^{1}$ Assistant Professor of Gastroenterology, ${ }^{2}$ Associate Professor, ${ }^{4}$ Senior Registrar, ${ }^{5,6}$ House Officers, Department of Medicine, ${ }^{3}$ Assistant \\ Professor of Medicine \& Endocrinology, Rehman Medical Institute, Peshawar \\ Correspondence to: Dr. Humaira Achakzai, Email: humairaachakzai@yahoo.com, Cell 0300-5952789
}

\begin{abstract}
Aims: To look for common indications and gastrointestinal pathologies observed on colonoscopy and to assess its diagnostic yield with respect to different clinical indications.

Study design: Observational cross-sectional study

Place and duration of study: Department of Medicine, Rehman Medical Institute from 1st January 2018 to $31^{\text {st }}$ March 2019

Methodology: Five hundred and seventy three patients referred for colonoscopy were included. The demographic profile, indication of colonoscopy and colonoscopy findings were noted.

Results: There were 231 (40.3\%) males and 342 (59.7\%) females with mean age $42.32 \pm 17.51$ years. Bleed per rectum was most common indication noted in 284 (49.6\%) followed by altered bowel habits 125 (21.8\%) cases. Two hundred and fifty two (44\%) colonoscopies were normal. One hundred and seventy three (30.2\%) revealed significant lesions and $148(25.8 \%)$ lesions were insignificant. Internal hemorrhoids were observed in $130(22.7 \%)$ followed by colitis in 54 (9.4\%). Abnormal computerized tomography abdomen revealed significant lesions in $62.2 \%$ of patients. Chronic diarrhea followed by constipation, altered bowel habits and iron deficiency anemia (IDA) showed $34.5 \%, 25.7 \%, 17.6 \%$ and $<10 \%$ significant lesions respectively.

Conclusion: Rectal bleed was the most common indication followed by altered bowel habits. Most common colonoscopy findings were hemorrhoids followed by colitis and abnormal growth. Abnormal computerized tomography abdomen gave the best diagnostic yield for colonoscopy.

Keywords: Colonoscopy, Indications, Diagnostic yield
\end{abstract}

\section{INTRODUCTION}

Lower gastrointestinal (GI) diseases constitute a broad spectrum of diseases ranging from benign polyps, infectious and inflammatory pathologies to autoimmune disease and malignancies. Ileitis, colitis, diverticula, infiltrative lesions, erosions, ulcers, angiodysplasia, inflammatory bowel disease (IBD), familial adenomatous polyposis (FAP), amebiasis, polyps, cancer, fissures, fistulas, hemorrhoids and rectal varices are some of the commonly encountered Lower GI pathologies. ${ }^{1}$

Diseases of the lower gastrointestinal tract are a significant cause of mortality and morbidity worldwide, with colorectal carcinoma accounting for more than half of all Gl tract malignancies; therefore making it the main cause of GI related mortality. It accounted for 52,394 deaths in the US alone in the year $2012^{2}$.

Colorectal diseases can have variable presentations therefore making it difficult to diagnose them on symptomatology alone. Some of the symptoms that are suggestive of lower Gl diseases include per rectal bleed, change in bowel habits, chronic diarrhoea and constipation, weight-loss and symptoms of anaemia or nutritional deficiencies. $^{3}$ A study conducted in 2012 in the U.S. revealed that per rectal bleed had an annual incidence of 20.5 in 100,000 in the general Western population and resulted in 1 to $2 \%$ of all hospital emergencies ${ }^{4}$.

Colonoscopy is considered the investigation of choice for diagnosing lower Gl diseases. It is used for screening, diagnostic and therapeutic purposes. Colonoscopy is

Received on 16-12-2020

Accepted on 17-04-2021 considered the most accurate test in detecting lower $\mathrm{G}$ pathologies that are suspected on clinical and radiological examinations ${ }^{5}$.

Different studies have described variable spectrum of lower Gl symptoms and pathologies on colonoscopies. In a study conducted in Pakistan, a major indication for colonoscopy was rectal bleeding followed by chronic diarrhoea. Colonoscopy findings in this study were normal in a significant number of patients while inflammatory bowel disease was most common pathological finding in this study 6 .

Yaqoob et $\mathrm{al}^{7}$ reported $50 \%$ of lower $\mathrm{Gl}$ endoscopies as normal. Lower GI endoscopy identified a problem that explained the symptoms in only $10 \%$ cases. Rectal bleeding was the most reliable symptoms and provided high diagnostic yield (67\%) of colonoscopy. A study conducted in Sri Lanka showed that rectal bleed followed by altered bowel habits was associated with appropriate colonoscopy findings of about $70 \%{ }^{8}$. Another study conducted in Karachi showed hemorrhoids to be the most commonly diagnosed pathology followed by ulcers ${ }^{9}$.

In our study we aimed to look for common indications and GI pathologies observed on colonoscopy at our tertiary care hospital and to assess its diagnostic yield with respect to different clinical indications. Rehman Medical Institute is 600 bedded tertiary care unit with a catchment area extending beyond borders to Afghanistan which allowed us to see variety of patients with different ethnicities.

\section{MATERIALS AND METHODS}

This was a cross sectional study was conducted at Rehman Medical Institute over a period of 15 months from 
$1^{\text {st }}$ January 2018 to $31^{\text {st }}$ March 2019 and comprised 573 patients. The demographic profile, indication of colonoscopy and referring doctor's specialty was noted. Colonoscopy was performed by an experienced consultant. Patients were given midazolam or rectal lignocaine or both as needed. Pain score was recorded as VRS scale. The subjects had to rate the possible changes in pain by one of five categorical descriptors: "much less pain," "a little less pain," "the same pain," "a little more pain," or "much more pain". ${ }^{10}$ Gut preparation, extent of colonoscopy and positive findings were noted. Diagnostic yield of indications was assessed by the percentage of significant lesions picked up on colonoscopy. ${ }^{11,12}$ Significant lesions were defined according to EPAGE II as malignant growth, Stenosis, Inflammatory bowel disease and angiectesias ${ }^{12}$. Data was entered and analyzed through SPSS-22. Student's T test and Chi Square tests were employed to look for statistical relation wherever indicated. $\mathrm{P}$ value $\leq 0.05$ was taken significant.

\section{RESULTS}

Two hundred and thirty one were (40.3\%) male cases and $342(59.7 \%)$ female cases. The cecum was achieved in 336 $(58.6 \%)$ of the patients undergoing colonoscopy. Lignocaine rectal gel and midazolam in combination were the most frequently used sedatives followed in frequency by midazolam alone and rectal gel. General surgery accounted for the most number of referrals followed by gastroenterology (Table 1).

Table1: Demographic information of the patients $(n=573)$

\begin{tabular}{|l|l|l|}
\hline Variable & No. & $\%$ \\
\hline Mean age (years) & $42.32 \pm 17.51$ \\
\hline Gender & 231 & 40.3 \\
\hline Male & 342 & 59.7 \\
\hline Female & 336 & 58.6 \\
\hline Cecal Intubation & 41.4 \\
\hline Yes & 237 & 78.0 \\
\hline No & 21.0 \\
\hline Gut Preparation & 451 & 5.4 \\
\hline Good & 122 & 21.6 \\
\hline Poor & 31 & 55.0 \\
\hline Sedation & 125 & 17.0 \\
\hline Lignocain Rectal Gel & 315 & 81.0 \\
\hline Midazolam & 102 & 11.6 \\
\hline Both & 464 & 4.4 \\
\hline None & 62 & 3.0 \\
\hline Pain Score & 25 & 52.9 \\
\hline VRS 1 & 17 & 8.9 \\
\hline VRS 2 & 38.2 \\
\hline VRS 3 & 303 \\
\hline VRS 4 & 51 & \\
\hline Referring Department & 219 & \\
\hline General Surgery & \\
\hline General Medicine & \\
\hline Gastroenterology &
\end{tabular}

Evaluation of per rectal bleed was the most common indication for performing a colonoscopy, accounting for 284 (49.6\%) of all colonoscopies performed followed by altered bowel habits in 125 (21.8) of the cases (Fig. 1). Per rectal bleeding was the most frequent indication for colonoscopy in all age groups, individuals aged 30 to 50 had the greatest frequency of PR bleed 121 (42.6\%). Iron deficiency anaemia and abnormal CT findings were more frequent in the age group 50-70 years $16(47.1 \%)$ and 13 $(35.1 \%)$ respectively.

Of all the colonoscopies performed, 252 (44\%) turned out to be normal. One hundred and seventy three (30.2\%) revealed lesions that were significant and 148 (25.8\%) revealed insignificant lesions. Figure 2 illustrates the pathologies diagnosed on colonoscopy in further detail.

An abnormal growth on colonoscopy was mostly found in individuals aged 51-70 years with a frequency of $18(37.5 \%)$, strictures were greatest in individuals aged 30 to 50 attributing to $5(62.5 \%)$ of all cases. Polyps had the greatest frequency in young adults aged less than 30 years 17 (43.6\%). IBD and colitis were more common in participants aged 30-51. Abnormal CT abdomen revealed significant lesions in $62.2 \%$ of patients. Chronic diarrhoea had $34.5 \%$ and constipation gave $25.7 \%$ positive diagnostic yield. $20.9 \%$ patients with bleeding per rectum had significant lesions. Altered bowel habits and IDA showed significant lesions only in $17.6 \%$ and $<10 \%$ respectively $[\mathrm{P}<0.05]$ (Table 2).

Fig. 1: Indications for colonoscopy

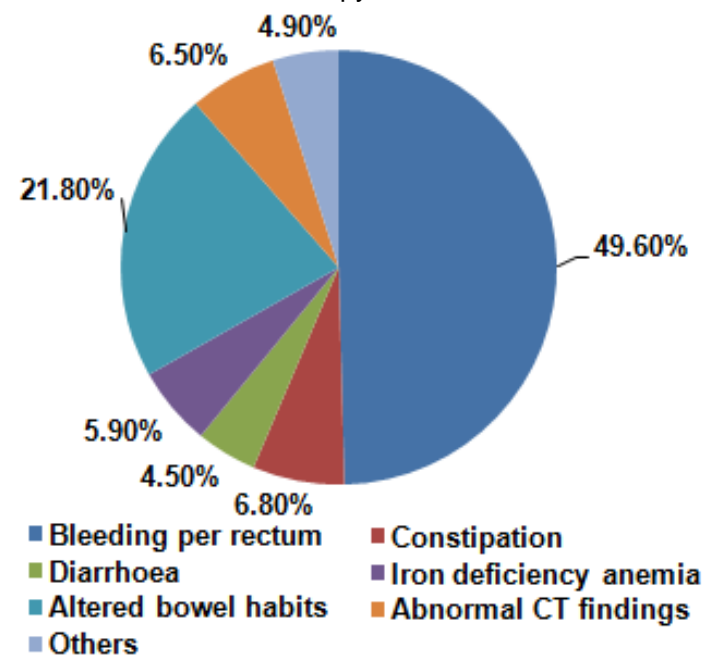

Fig. 2: Pattern of colonoscopic findings

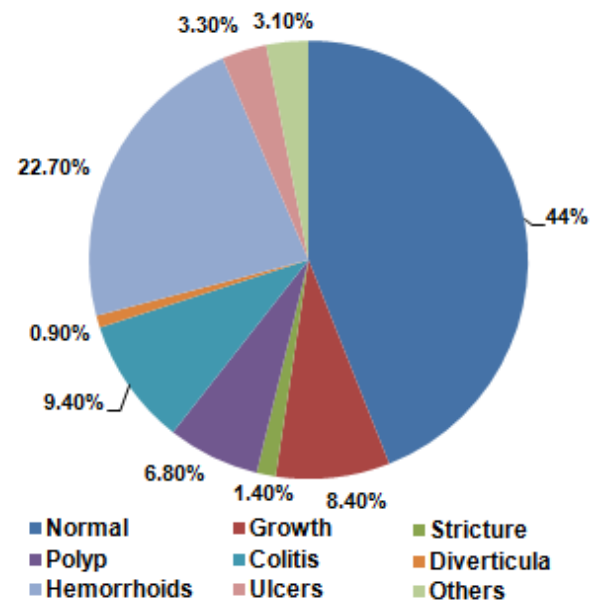


Table 2: Frequency of colonoscopy findings in different indications

\begin{tabular}{|c|c|c|c|c|c|c|c|c|c|}
\hline \multirow{2}{*}{$\begin{array}{l}\text { Colonoscopy } \\
\text { Indications }\end{array}$} & \multicolumn{9}{|c|}{ Colonoscopy findings } \\
\hline & Normal & Growth & Stricture & Polyp & Colitis & Diverticula & Hemorrhoids & Ulcers & Others \\
\hline PR bleed & $\begin{array}{l}33.5 \% \\
(n=95)\end{array}$ & $\begin{array}{l}5.3 \% \\
(n=15)\end{array}$ & $\begin{array}{l}0.4 \% \\
(n=1)\end{array}$ & $\begin{array}{c}9.5 \% \\
(n=27)\end{array}$ & $\begin{array}{c}9.9 \% \\
(n=28)\end{array}$ & $\begin{array}{l}0.7 \% \\
(n=2)\end{array}$ & $\begin{array}{l}34.5 \% \\
(n=98)\end{array}$ & $\begin{array}{c}4.6 \% \\
(n=13)\end{array}$ & $\begin{array}{l}1.8 \% \\
(n=5)\end{array}$ \\
\hline Constipation & $\begin{array}{c}59 \% \\
(n=23)\end{array}$ & $\begin{array}{l}2.6 \% \\
(n=1) \\
\end{array}$ & $\begin{array}{l}12.8 \% \\
(\mathrm{n}=5)\end{array}$ & $\begin{array}{l}2.6 \% \\
(n=1) \\
\end{array}$ & $\begin{array}{l}2.6 \% \\
(\mathrm{n}=1)\end{array}$ & $\begin{array}{l}5.1 \% \\
(\mathrm{n}=2) \\
\end{array}$ & $\begin{array}{l}10.3 \% \\
(n=4)\end{array}$ & $\begin{array}{l}2.6 \% \\
(n=1)\end{array}$ & $\begin{array}{l}2.6 \% \\
(n=1) \\
\end{array}$ \\
\hline Diarrhea & $\begin{array}{l}61.5 \% \\
(n=16)\end{array}$ & $\begin{array}{l}11.5 \% \\
(n=3)\end{array}$ & $\begin{array}{l}3.8 \% \\
(n=1)\end{array}$ & - & $\begin{array}{l}15.4 \% \\
(n=4)\end{array}$ & - & - & $\begin{array}{l}3.8 \% \\
(n=1)\end{array}$ & $\begin{array}{l}3.8 \% \\
(n=1)\end{array}$ \\
\hline IDA & $\begin{array}{l}76.5 \% \\
(n=26)\end{array}$ & $\begin{array}{l}2.9 \% \\
(n=1)\end{array}$ & - & $\begin{array}{l}2.9 \% \\
(\mathrm{n}=1)\end{array}$ & $\begin{array}{l}2.9 \% \\
(n=1)\end{array}$ & - & $\begin{array}{l}8.8 \% \\
(\mathrm{n}=3) \\
\end{array}$ & $\begin{array}{l}2.9 \% \\
(n=1)\end{array}$ & $\begin{array}{l}2.9 \% \\
(n=1)\end{array}$ \\
\hline abnormal CT & $\begin{array}{l}29.7 \% \\
(n=11)\end{array}$ & $\begin{array}{l}51.4 \% \\
(n=19)\end{array}$ & $\begin{array}{l}2.7 \% \\
(n=1)\end{array}$ & - & $\begin{array}{l}5.4 \% \\
(\mathrm{n}=2) \\
\end{array}$ & $\begin{array}{l}2.7 \% \\
(\mathrm{n}=1) \\
\end{array}$ & - & - & $\begin{array}{l}8.1 \% \\
(n=3) \\
\end{array}$ \\
\hline $\begin{array}{l}\text { Altered bowel } \\
\text { habits }\end{array}$ & $\begin{array}{l}57.6 \% \\
(n=72)\end{array}$ & $\begin{array}{l}6.4 \% \\
(\mathrm{n}=8)\end{array}$ & - & $\begin{array}{l}3.2 \% \\
(n=4)\end{array}$ & $\begin{array}{l}10.4 \% \\
(n=13)\end{array}$ & - & $\begin{array}{l}19.2 \% \\
(\mathrm{n}=24)\end{array}$ & $\begin{array}{l}0.8 \% \\
(n=1)\end{array}$ & $\begin{array}{l}2.4 \% \\
(n=3)\end{array}$ \\
\hline Others & $\begin{array}{c}32.1 \% \\
(n=9)\end{array}$ & $\begin{array}{l}3.6 \% \\
(n=1)\end{array}$ & - & $\begin{array}{l}21.4 \% \\
(n=6)\end{array}$ & $\begin{array}{l}17.9 \% \\
(n=5)\end{array}$ & - & $\begin{array}{l}3.6 \% \\
(n=1)\end{array}$ & $\begin{array}{l}7.1 \% \\
(n=2)\end{array}$ & $\begin{array}{c}14.3 \% \\
(n=4)\end{array}$ \\
\hline
\end{tabular}

\section{DISCUSSION}

In our study mean age of patients was $42 y$ rs. All guidelines recommend this screening procedure above 50 years, if done under it must have some appropriate indication for it. ${ }^{9}$ Our study population was comparatively young as compared to some studies $9,11,13$. On the other hand studies conducted in 2 cities of Pakistan showed results similar to our study ${ }^{14,15}$.

In our study females were more; this is concordant with a study conducted by Joukar et $\mathrm{al}^{16}$ and Alvi ${ }^{17}$ while other studies documented more males having lower $\mathrm{Gl}$ pathologies undergoing colonoscopy ${ }^{9,18,19}$. Cecal intubation rate was $58.6 \%$ in our study. A study from Islamabad described only $42 \%$ complete exploration rate ${ }^{7}$. While in other studies it as higher as $80 \%{ }^{15}$. The reason for this can be multifactorial like poor gut preparation, excessive bowel looping, participant discomfort and impassable and nonnegotiable obstructing lesions or cancers of large bowel $7,20,21$.

Rectal bleeding was the most common indication of colonoscopy followed by altered bowel habits, well supported by a study ${ }^{8}$. Bleeding per rectum was most common indication for colonoscopy in other studies as well6,15.

Regarding colonoscopic findings, $44 \%$ patients had normal colonoscopy. Studies at different centers of Pakistan described relatively less number of normal colonoscopies $30 \%{ }^{9}$ and $22 \% .{ }^{15}$ However two other studies revealed $50 \%$ of normal colonoscopies ${ }^{7,8}$. The reason for the difference in diagnostic yield was mainly the appropriateness of indications for which the procedure was being performed.

The most common positive finding in our study was hemorrhoids. This is supported by another study in literature ${ }^{9,15,16}$. Colitis and abnormal growth were the next most common findings. These two were observed commonly in other studies ${ }^{6,15}$.

Regarding diagnostic yield, Abnormal abdominal CT scan was the most reliable indication directing towards positive yield of colonoscopy. It is supported by another study by Colvin et $\mathrm{al}^{22}$ which stated that suspicious CT scan warrants further investigation. Altered bowel habits and IDA showed markedly less number of significant lesions hence contributing to a low diagnostic yield. Only a couple of studies have been done that focused on diagnostic yield of different indications. In one study, the patients with altered bowel habits had the diagnostic yield of $29 \% .^{7}$ In another study it was $39.6 \% .^{8}$ In a large multicenter study, anaemia and altered bowel habits gave a very high yield of colonoscopy ${ }^{23}$. There is a difference in indication of colonoscopy in terms of diagnostic yield even in guidelines published by two societies. ${ }^{12}$ Further studies in our setup should be performed to clarify the difference in this regard.

Rectal bleeding was the most common indication for colonoscopy in our study and hemorrhoids were the most common finding that correlated well with the indication. Diagnosis of hemorrhoids could have been done even on sigmoidoscopy. ${ }^{24}$ Thus, it is logical to perform relevant procedure according to indication, especially where there is limited manpower and facilities ${ }^{25}$. Only in high risk patients with relevant symptoms, abnormal non-invasive investigations and sigmoidoscopy negative patients should colonoscopy be performed to reach the diagnosis ${ }^{26}$. Our study has a limitation. It is a single hospital based study so we can only give frequency data.

\section{CONCLUSION}

The colonoscopy was done for rectal bleed in most cases, followed by altered bowel habits. Most common colonoscopy findings were hemorrhoids followed by colitis and abnormal growth. $44 \%$ of colonoscopies were normal and only $30.2 \%$ showed significant lesions. Abnormal CT abdomen gave the best positive diagnostic yield for colonoscopy.

\section{REFERENCES}

1. Bafandeh Y, Yazdanpanah F. Distribution pattern of colorectal diseases based on 2300 total colonoscopies. Gastroenterol Hepatol Bed Bench 2017; 10(2):90-96.

2. Anne P, Evan D, Jennifer L, Nicholas CS. Burden of Gastrointestinal Disease in the United States: 2012 Update. Gastroenterology 2012; 143:1179-1187.e3.

3. Rex DK, Schoenfeld PS, Cohen J, Pike IM, Adler DG, Fennerty BM, et al. Quality Indicators for Colonoscopy. Am J Gastroenterol 2015; 110(1):72-90.

4. Kang L, Patel J, Ha TV, Navuluri R. Acute Lower Gastrointestinal Bleeding. Seminars Interventional Radiol 2012;29(03):178-86.

5. Rex DK, Bond JH, Winawer S, Levin TR, Burt RW, Johnson $\mathrm{DA}$, et al. Quality in the technical performance of 
colonoscopy and the continuous quality improvement process for colonoscopy: recommendations of the US. MultiSociety Task Force on Colorectal Cancer. Am J Gastroenterol 2002;97(6):1296-308.

6. Amjad S, Ammara A, Sobia Z, Arooj E. Colonoscopy: Analysis of indications and diagnoses at a specialist unit. Ann Pak Inst Med Sci 2010;6:15-9.

7. Yaqoob N, Abbasi S, Durrani A A. Is lower Gl endoscopy still a problem? J Gastroenterol Hepatol Res 2012; 1(7): 122-6

8. Samarakoon Y, Gunawardena N, Pathirana A, Hewage S. Appropriateness of colonoscopy according to EPAGE II in a low resource setting: a cross sectional study from Sri Lanka. BMC Gastroenterol 2018;18(1):72.

9. Mohammad S, Channa GH, Shah IA, Baloch I, Shah AA Lakho S, Ahmed A, Channa AA, Sachdev P, Shaukat F. Colonoscopy findings: a single institution study from Pakistan. Cureus 2019;11(11).

10. Bech RD, Lauritsen J, Ovesen O, Overgaard S. The verbal rating scale is reliable for assessment of postoperative pain in hip fracture patients. Pain Res Treatment 2015;2015.

11. Al-Najami I, Rancinger CP, Larsen MK. The diagnostic yield of colonoscopy stratified by indication. Gastroenterol Res Pract 2017;2017:1

12. Gimeno-García AZ, Quintero E. Colonoscopy appropriateness: Really needed or a waste of time?. World J Gastrointestinal Endoscopy 2015; 7(2):94.

13. Sultana N, Khan S, Baloch SU. Diagnostic accuracy of contrast enhanced computed tomography in staging of colorectal carcinoma. PAFJM 2018;68(5):1076-81

14. Rasool S, Ahmed S, Siddiqui S, Salih M, Jafri W, Hamid S. Evaluation of quality and patient satisfaction during endoscopic procedure: a cross sectional study from south Asian country. J Pak Med Assoc 2010;60(12):990.

15. Rehman KU, Qureshi MO, Khokhar N, Shafqat F, Salih M. Quality of colonoscopy and spectrum of lower gastrointestinal disease as determined by colonoscopy. J Coll Physicians Surg Pak 2015; 25: 478-81.

16. Joukar F, Majd SK, Fani A, Nazari N, Mansour-Ghanaei F. Colonoscopy outcome in North of Iran (Guilan): 2006-2009. Int J ClinExp Med 2012, 5:321-325.
17. Alvi H, Rasheed T, Shaikh MA, Ali FS, Zuberi BF, Samejo AA. Impact of bowel preparation on caecal intubation time during colonoscopy. Pak J Med Sci 2019;35(6):1516.

18. Betés M, Munoz-Navas MA, Duque JM, Angós R, Macías E, Súbtil JC, et al. Use of colonoscopy as a primary screening test for colorectal cancer in average risk people. Am J Gastroenterol 2003;98(12):2648-54.

19. Imperiale TF, Wagner DR, Lin CY, Larkin GN, Rogge JD, Ransohoff DF. Results of screening colonoscopy among persons 40 to 49 years of age. NEJM 2002; 346(23):1781-5.

20. Marshall JB, Brown DN. Photodocumentation of total colonoscopy: how successful are endoscopists? Do reviewers agree? Gastrointest Endosc 1996; 44: 243-8.

21. Rex DK. Still photography versus videotaping for documentation of cecal intubation: a prospective study. Gastrointest Endosc 2000; 51: 451-9.

22. Colvin H, Lukram A, Sohail I, Chung KT, Jehangir E, Berry J, Babu $\mathrm{H}$, Hinson $\mathrm{F}$. The performance of routine computed tomography for the detection of colorectal cancer. Ann Royal Coll Surgeons Engl 2013;95(7):473-6.

23. Marzo-Castillejo M, Almeda J, Mascort JJ, Cunillera O, Saladich R, Nieto R, et al. Appropriateness of colonoscopy requests according to EPAGE-II in the Spanish region of Catalonia. BMC Family Practice 2015;16(1):154.

24. Hussain F, Farooq MA, Farooq Y, Khan MA. Flexible Sigmoidoscopic Findings In Evaluation Of Bleeding Per Rectum In Young Patients. Pak J Physiol 2016; 12(4):24-6.

25. Lim CS, McGeever L, Grey JH, Krishna A. How important is it to investigate the whole of the colon after initial assessment at a rapid access colorectal clinic. Int $\mathrm{J}$ Colorectal Dis 2009; 24; 1341-5.

26. Iqbal S, Krishna M, Fuad H. Appropriateness of indication and diagnostic yield of colonoscopy: First report based on the 2000 guidelines of the American Society for Gastrointestinal Endoscopy. World J Gastroenterol 2005; 11(44):7007-13. 